\title{
Teknik Penjadwalan Prosesor FIFO, SJF Non Preempetive, Round Robin
}

\author{
Ikhsan Parinduri', Siti Nurhabibah Hutagalung² \\ 1,2 STMIK Budi Darma \\ ikhsanparinduri9@gmail.com,siti_nurhabibah69@yahoo.com
}

\begin{abstract}
Processor scheduling is divided into several methods including FIFO, Non Preempetive SJF, Round Robin. Implementation can know the performance of the processor which consists of process, waiting time, arrival time and completion stage. In this case the processor scheduling is made in NetBeans IDE.7.0.1 programming with input on the main menu and calculation process display menu with AWT (Average Waiting Time) value with units of ms, table display process: process, burst time and gaint chart : process, waiting time, start time and end time.
\end{abstract}

Keywords: Processor Scheduling, FIFO, Non Preempetive SJF, Round Robin.

Abstrak- Penjadwalan prosesor terbagi dalam beberapa metode diantaranya FIFO, SJF Non Preempetive, Round Robin. Implementasi dapat mengetahui kinerja dari prosesor yang terdiri dari proses, waktu tunggu, waktu tiba dan tahap penyelesaian. Dalam hal ini penjadwalan prosesor dibuat pada pemprograman NetBeans IDE.7.0.1 dengan inputan pada menu utama dan menu tampilan proses perhitungan dengan nilai AWT (Average Waiting Time) dengan satuan dengan satuan ms., proses tampilan tabel : proses, burst time dan gaint chart : proses, waktu Tunggu, Waktu mulai dan waktu berakhir.

Kata kunci : Penjadwalan Prosesor, FIFO, SJF Non Preempetive, Round Robin.

\section{I . PENDAHULUAN}

Berbicara teknik penjadwalan prosesor, termasuk kedalam kurikulum materi perkuliahan sistem operasi, arsitektektur dan organisasi komputer. Pembagiannya yaitu penjadwalan jangka pendek (short-term scheduller), jangka menengah (medium-term scheduller) dan jangka panjang (long-term scheduller).

Penjadwalan proses merupakan komponen penting pada sistem operasi, yang bertujuan untuk memaksimalkan penggunaan CPU dan meningkatkan produktivitas komputer. Penjadwalan bertugas melakukan pergantian proses yang dieksekusi, dan digunakan saat dua atau lebih proses mengirimkan sinyal yang menandakan kedatangan proses tersebut secara simultan. Pada processor yang berinti tunggal, sistem operasi menentukan proses yang dieksekusi terlebih dulu sesuai prioritasnya. Pengaturan proses ini ditangani oleh scheduler, dengan menggunakan suatu algoritma penjadwalan [1]. Untuk melakukan penjadwalan, strategi Penjadwalan dibagi ke dalam 2 diantaranya adalah penjadwalan nonpreemptive (ketika proses diberi jatah waktu penggunaan prosessor maka prosessor tidak dapat diambil alih proses lain, sampai prose situ selesai dan penjadwalan preemptive (ketika proses diberi jatah jatah waktu penggunaan

Teknik Penjadwalan Prosesor FIFO, SJF Non Preempetive, Round Robin (Ikhsan Parinduri) | 864 
prosessor, maka proses tersebut dapat diambil alih proses lain, sehingga proses tersebut disela sebelum selesai, dan harus dilanjutkan menunggu sampai jatah waktu prosessor tiba) [2]. Prosedur lagkah penjadwalan dikenal dengan algoritma, algortitma yang menerapkan strategi nonpreemptive antara lain: First In First Out (First Come First Serve), Shortest Job First (SJF), Highest Ratio Next, Multiple Feedback Queue. Sedangkan algoritma yang menerapkan strategi preemptive adalah Round Robin, Shortest Remaining First, Priority Schedulling, Guaranted Schedulling. Algoritma adalah urutan logis langkah-langkah penyelesaian masalah. Masalah tersebut dapat berupa apa saja, dengan catatan untuk setiap masalah, ada kriteria kondisi awal yang harus dipenuhi sebelum menjalankan algoritma. Algoritma akan dapat selalu berakhir untuk semua kondisi awal yang memenuhi kriteria, dalam hal ini berbeda dengan heuristik. Algoritma sering mempunyai langkah pengulangan (iterasi) atau memerlukan keputusan (logika Boolean dan perbandingan) sampai tugasnya selesai, [3].

Beberapa kriteria untuk mengukur kinerja pendawalan diantaranya adalah Adil (Fairness), Efisiensi (Eficiency), Waktu tanggap (Response Time). Waktu tanggap berbeda untuk :

a. Sistem interaktif

Didefinisikan sebagai waktu yang dihabiskan dari saat karakter terakhir dari perintah dimasukkan atau transaksi sampai hasil pertama muncul di layar. Waktu tanggap ini disebut terminal response time.

b. Sistem waktu nyata

Didefinisikan sebagaiwaktu dari saat kejadian (internal atau eksternal) sampai instruksi pertama rutin layanan yang dimaksud dieksekusi, disebut event response time. Sasaran penjadwalan adalah meminimalkan waktu tanggap.

c. Turn Around Time (TAT)

Yaitu waktu yang yang dihabiskan dari saat program (job) mulai masuk kesistem sampai proses diselesaikan sistem. Sasaran penjadwalan adalah meminimalkan Turn Around Time.

d. Throughput

Yaitu jumlah kerja yang dapat diselesaikan dalam satu unit waktu. Sasaran penjadwalan adalah memaksimalkan jumlah job yang diproses persatu interval waktu. Kriteria-kriteria tersebut saling bergantung dan dapat pula saling bertentangansehingga tidak dimungkinkan optimasi semua kriteria secara simultan.

Sasaran penjadwalan berdasarkan kriteria-kriteria optimasi tersebut :

a. Menjamin tiap proses mendapat pelayanan dari pemroses yang adil.

b. Menjaga agar pemroses tetap dalam keadaan sibuk sehingga efisiensi mencapai maksimum. Pengertian sibuk adalah pemroses tidak menganggur,termasuk waktu yang dihabiskan untuk mengeksekusi program pemakai dansistem operasi.

c. Meminimalkan waktu tanggap.

d. Meminimalkan turn arround time. 
e. Memaksimalkan jumlah job yang diproses persatu interval waktu. Lebih besarangka throughput, lebih banyak kerja yang dilakukan sistem.

\subsection{FCFS / FIFO (FIRST IN FIRST OUT)}

FCFS/FIFO bisa diartikan sebagai Proses yg tiba lebih dahulu akan dilayani lebih dahulu. Jika ada proses tiba pada waktu yg sama, maka pelayanan mereka dilaksanakan melalui urutan mereka dalam antrian. Proses di antrian belakang harus menunggu sampai semua proses di depannya selesai. Setiap proses yang berada pada status ready dimasukkan ke dalam FCFS queue (strutur data antrian) sesuai dengan waktu kedatangannya.

Dirumuskan :

TA $=$ Waiting Time + Length Of Execution
Keterangan : Turn Arround Time (TA) = Waktu penyelesaian
Waiting time = Waktu tunggu
Length Of Execution = Lama Eksekusi

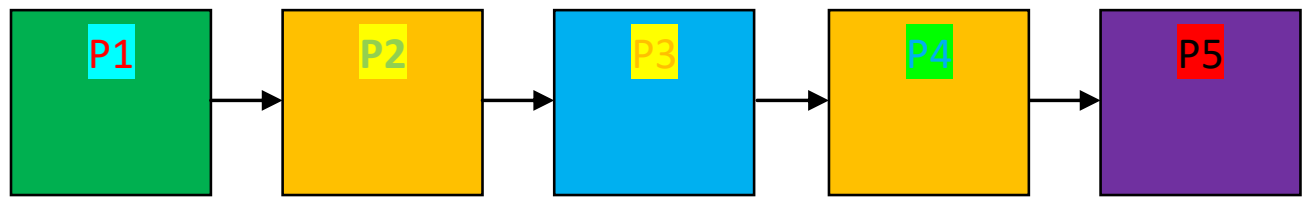

Gambar 1. Proses Penjadwalan Prosesor

\subsection{Shortest Job First (SJF)}

Setiap proses yang ada di ready queue akan dieksekusi berdasarkan burst time terkecil. Mengakibatkan waiting time yang pendek untuk setiap proses dan waiting time rata-ratanya juga menjadi pendek, sehingga dapat dikatakan ini adalah algoritma yang optimal.

\subsection{Algoritma Round Robin (RR)}

Round Robin adalah penjadwalan proses menerapkan strategi preemptive, bukan di-preempt oleh proses lain, tapi terutama oleh penjadwal berdasarkan jatah waktu pemroses yang disebut kwanta (quantum, [4]. Algoritma Round Robin disebut juga Fair Time Scheduling, memiliki prinsip dasar, yaitu semua sumber antrian dianggap sama sehingga diberi waktu yang disebut time quantum. Jika time quantum habis atau proses selesai, maka proses berlanjut ke antrian berikutnya. Secara spesifik, penjadwalan ini akan menjadwalkan user-j pada TTI (Transmission Time Interval) ke-k jika :

User-j $=\bmod ((\mathrm{k}-1), \mathrm{N})+1(1)$

$\mathrm{N}$ adalah jumlah user yang sedang aktif dalam sistem. 
Dari persamaan tersebut terlihat bahwa teknik penjadwalan ini independen terhadap kondisi propagasi maupun karakteristik kanal, sehingga tidak menganggap adanya keragaman kondisi multi-user. Dari permasalahan diatas, penulis membuat suatu penjadwalan prosesor Fifo, SJF Non Preempetive, Round Robin menggunakan program NeatBean IDE 7.0.1.

\section{METODOLOGI PENELITIAN}

\subsection{Perancangan Sistem}

Tahapan-tahapan pda perancangan sistem pada algoritma penjadwalan prosesor dibagi dalam beberapa tahapan :

\subsubsection{Struktur Menu}

Beberapa struktur menu untuk tampilan diantaranya adalah pada gambar berikut ini :

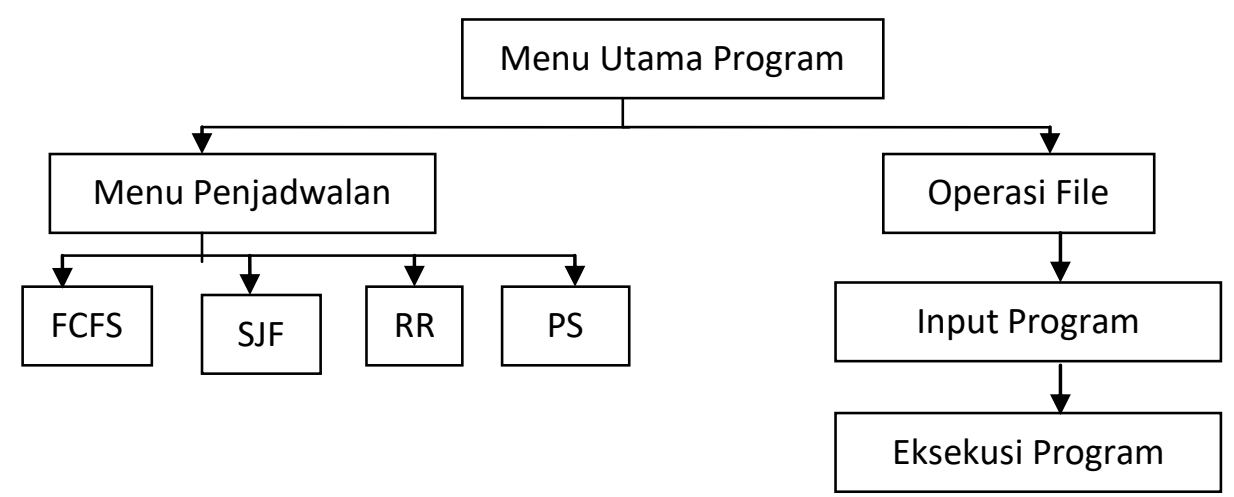

Gambar 2. Struktur Menu

\subsubsection{Desain Sistem}

Desain sistem menceritakan tentang langkah-langkah logika proses program penjadwalan prosesor. menu yang ditampilakan terdiri dari menu halaman utama, input program sampai dengan output program pada aplikasi menu ekseskusi proses program.

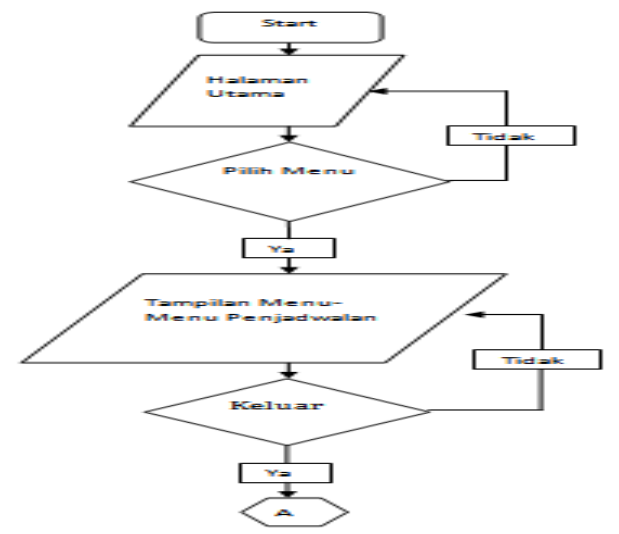

Gambar 3. Desain Sistem

\subsubsection{Perancangan Menu Antar Muka}

Teknik Penjadwalan Prosesor FIFO, SJF Non Preempetive, Round Robin (Ikhsan Parinduri) | 867 
Menu antar muka pada program penjadwalan terdiri dari menu P.CPU dan Operasi File. Pengisian inputan untuk progran menu penjadwalan harus disesuaikan dengan arrival time, burs time, AWT, kemudian dilakukan proses penampilan output pada hasil.

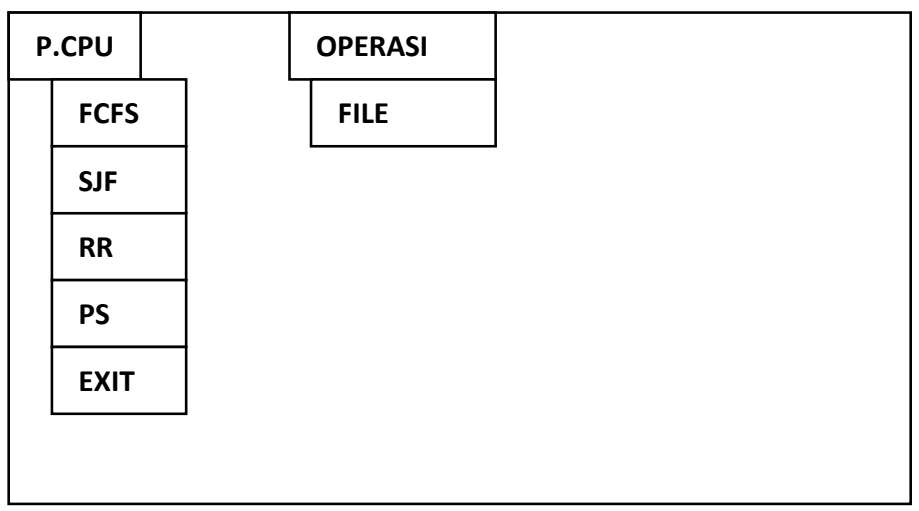

Gambar 4. Menu Antar Muka

\section{HASIL DAN PEMBAHASAN}

\subsection{Implementasi Program}

Implementasi merupakan taahapan pengkodena dari hasil perancangan. Program algoritma ini dapat digunakan untuk mempelajari proses berjalannya sebuah algoritma dan juga dasar-dasar teori dari algoritma tersebut. Dalam hal ini algortitma penjadwalan prosesor. Susunan dari program algoritma penjadwalan ini terdiri dari sekumpulan metode-metode penjadwalan yang terdiri dari FCFS, SJF, RR yang terintegrasi antra satu dengan yang lainnya. Sehingga membentuk sebuah aplikasi pembelajaran algoritma penjadwlan prosesor yang utuh.

\subsubsection{Halama Utama}

Pada tahapan implementasi ini, penulis terlebih dahulu akan menjelaskan apa saja komponen dalam sistem. Kemudian cara kerja fasilitas yang ada pada sistem yang terdiri dari tampilan antarmuka halam utama dari sistem.

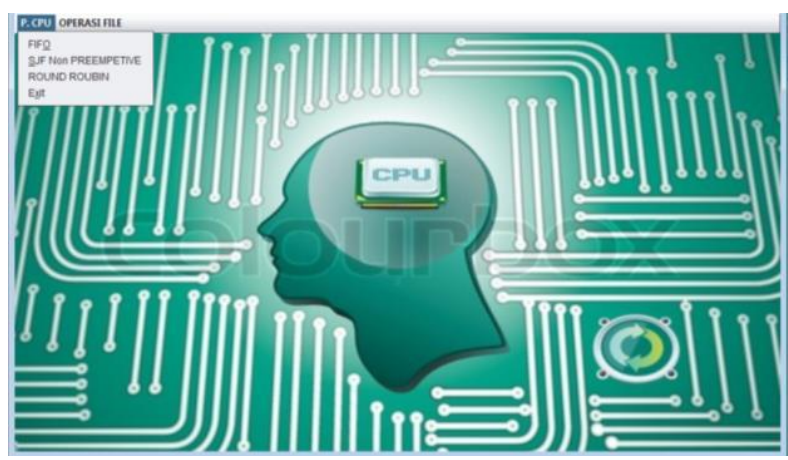

Gambar 5. Tampilan Halaman Utama 
Tampilan halaman utama terdiri dari P.CPU, P.CPU terbagai 4 menu FIFO, SJF Non Preempetive, Round Robin dan Exit.

\subsubsection{Menu FIFO}

Tampilan untuk Menu Fifo terdapat beberapa tampilan input data diantaranya adalah Input Proses, , Input Burst Time, AWT, Tabel : Proses, Burst Time, Gain Chart : proses, waktu tunggu, Nilai AWT, terlihat pada gambar.6 berikut ini :

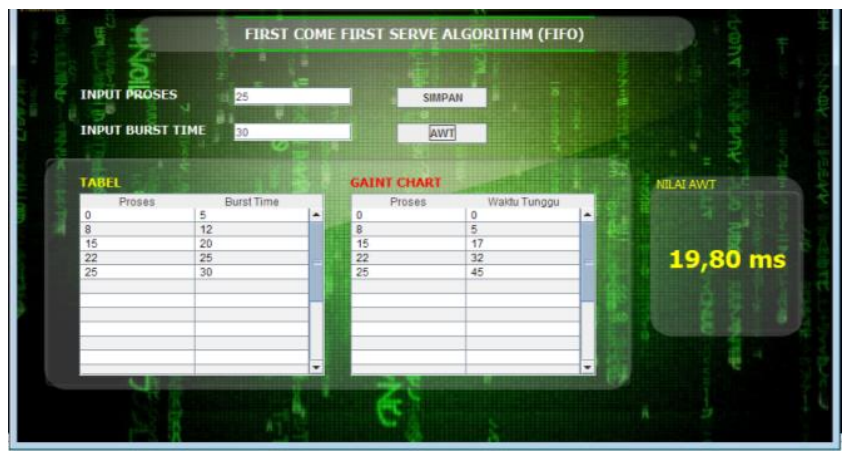

Gambar 6. Tampilan Menu Penjadawalan FIIFO

\subsubsection{Menu SJF Non Preempetive}

Tampilan menu untuk penjadwalan SJF Non Preempetive terdiri dari Input Proses, Input Burst Time, Input Waktu Tiba, Tabel : Proses, Tabel : Proses, Burst Time, Waktu Tiba, AWT, Gaint Chart : Proses, Waktu Tunggu dan Nilai AWT, terlihat pada gambar 7. berikut ini :

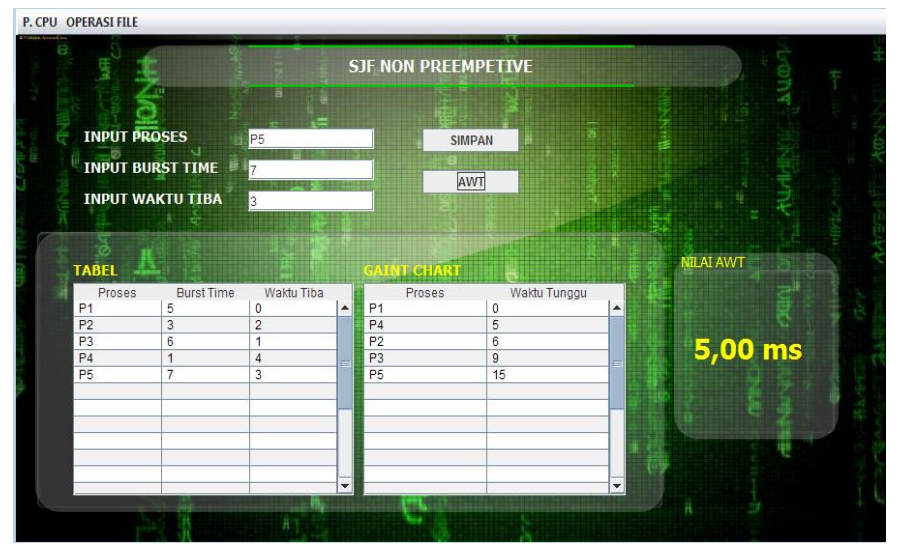

Gambar 7. Tampilan Menu Penjadawalan FIIFO

\subsubsection{Menu Round Robin}

Tampilan menu penjadwalan Round Robin teriri dari Input Proses, Input Burst Time, Quantum Time, AWT, Tabel : Proses, Burst Time, Gaint chart: Proses, Start Time, Stop Time, terlihat pada gambar 8, berikut ini : 


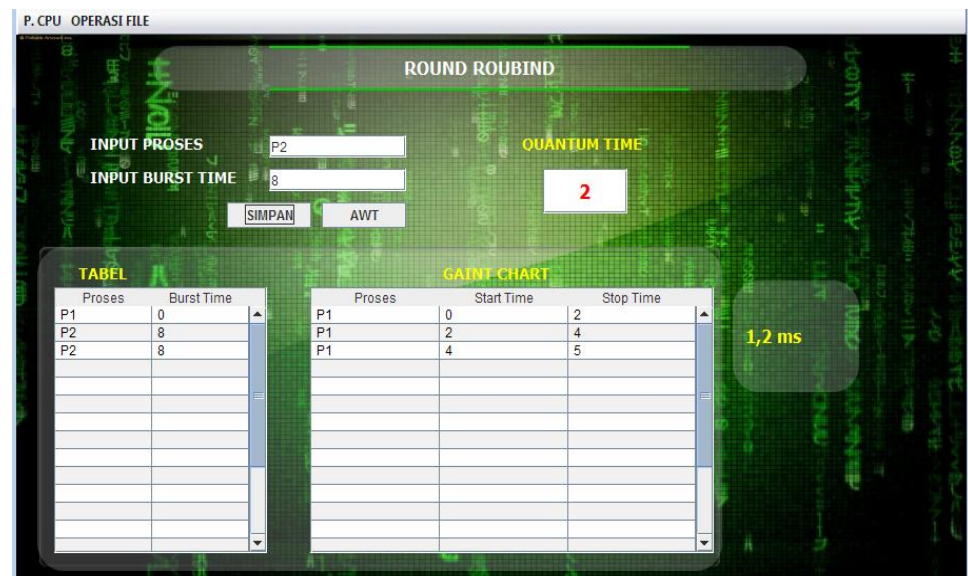

Gambar 8. Tampilan Menu Penjadwalan Round Robin

\subsubsection{Coding Program}

Coding program yang digunakan menggunakan aplikasi pemprograman NetBean IDE 7.0.1. Penginputan Coding progam terbagi dalam beberapa tahapan dengan melihat dari kebutuhan yang ada, terlihat pada gambar 9, berikut ini :

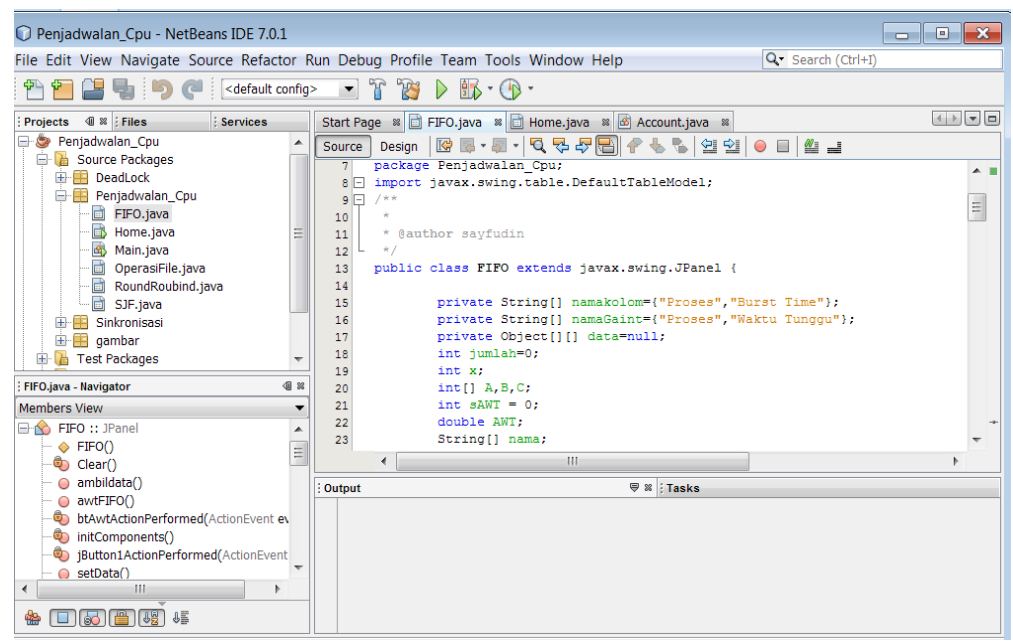

Gambar 9. Inputan Coding Program

\subsection{Pembahasan}

Pada algoritma penjadwalan prosesor ada beberapa yang harus diperhatikan dalam penginputan data :

a. Waktu Tiba yaitu akan menentukan nilai dari proses penjadwalan prosesor. Dimana waktu tunggu dapat dilihat dari inputan awal dari suatu kinerja prosesor.

b. Waktu Burst time yaitu jumlah waktu tunggu akan menentukan jumlah lama proses prossor melakukan kegiatan. Jika Burst time rendah, pada proses 
penjadwalan FIFO dan SJF Non Preemtive penjadwalan proses dilakukan terlebih dahulu.

c. Quantum Time yaitu nilai dapat dilihat dari waktu burst time awal atau nilai burst time yang terkecil, dapat digunakan pada penjadwalan Round Robin.

\section{KESIMPULAN}

Penjadwalan prosesor dapat diaplikasikan pada pemprogram NetBean IDE 7.0.1 dengan menyusun nilai-nilai inputan : proses, waktu tiba, waktu tunggu dan burst time yang kita inginkan. Dengan adannya algoritma penjadwalan prosesor kita dapat melihat efisiensi, waktu penyelesaian (Turn Around Time), penyampaian hasil kerja (Throughput) dan waktu tinggu (waiting time) dari suatu kinerja prosesor.

\section{DAFTAR PUSTAKA}

[1] Ardi Wijaya, Gunawan, "Implementasi Algoritma Round Robin Pada Sistem Penjadwalan Mata Kuliah (Studi Kasus: Universitas Muhammadiyah Bengkulu)",Jurnal Informatika UPGRIS Vol. 4, No. 1, (2018) P/E-ISSN: 2460-4801/2447-6645, Program Studi Informatika, Fakultas Teknik, Universitas Muhammadiyah Bengkulu.

[2] Tan Handoko Daharma Saputro," Pemodelan CPU Schedulling dengan Algoritma Round Robin Sebagai Media Pembelajaran Matakuliah Sistem Operasi", Program Studi Teknik Informatika, S1, Fakultas Ilmu Komputer, Universitas Dian Nuswantoro.

[3] Yogie Ariyanto P, Soetam Rizky Wicaksono, "Sistem Pendukung Keputusan Penjadwalan Pengemudi dengan Menggunakan Algoritma Round Robin (Studi Kasus: Zena Travel)", Jurnal Sains dan Teknologi, P-ISSN : 2303-3142 E-ISSN : 2548-8570 Vol. 6, No. 1, April 2017, Jurusan Sistem Informasi, Fakultas Sains dan Teknologi Universitas Ma Chung, Malang.

[4] Yosef Benny Kurniawan, "Aplikasi Simulasi Algoritma Penjadawalan Sistem Operasi”, 2011, Program Studi Teknik Informatika, Jurusan Teknik Informatika, Fakultas Sains dan Teknologi, Universitas Sanata Dharma, Yogyakarta

[5] D. Nofriansyah, Buku Algoritma Data Mining dan Pengujian, 2017. 